\title{
Occurrence of Dental Disorders in Dogs
}

\author{
Leonardo Sauer ${ }^{1}$, Nina Gabriela Silva Gualberto Oliveira ${ }^{2}$, Lorena Priscila Oliveira Andrade ${ }^{2}$, Elisângela \\ Barboza da Silva ${ }^{3}$, Mário Sérgio Lima de Lavor ${ }^{3}$, Amauri Arias Wenceslau ${ }^{3}$ \& Renata Santiago Alberto Carlos ${ }^{3}$
}

\begin{abstract}
Background: The anatomy of the canine oral cavity and its variations should be understood to facilitate clinical and surgical approaches. Several conditions can be identified during inspection of the oral cavity, including persistent deciduous teeth, enamel hypoplasia, gingival retraction, tooth abrasion and mobility, absence of dental elements, and periodontal disease. The aim of the present study was to determine the occurrence of dental disorders in dogs older than one year, from the microrregion Ilhéus - Itabuna, Bahia, Brazil.
\end{abstract}

Materials, Methods \& Results: A total of 74 dogs were evaluated immediately prior to surgical procedures for periodontal disease treatment. After visual inspection and examination with a millimeter probe, the dogs were classified into three groups according to the degree of periodontal disease. All other findings were recorded on an odontogram. Of the 74 dogs, 23 were classified as mild periodontal disease (mean age, 3.6 years), 26 as moderate periodontal disease (mean age, 5.7 years), and 25 as severe periodontal disease (mean age, 9.7 years). There was significant correlation $(0.7 p \leq 0.01)$ between age and severity of periodontal disease. Fifteen of the $74 \mathrm{dogs}$ did not present any other dental disorder than periodontal disease. Of the remaining 59, nine showed a single dental problem, and 50 had more than one dental problem. Six dogs (of the breeds Pinscher, Yorkshire Terrier, and Lhasa Apso) had deciduous teeth. Of the nine deciduous teeth, all were canine (dental elements 104, 204, and 304). Ten dogs had dental fractures and of the 11 fractured teeth, three were canine (dental elements 104 and 404). Dental wear was observed in 25 dogs (154 teeth). Of the evaluated dogs, seven showed furcation defects and 10 had teeth mobility. Dental absence was observed in 47 dogs.

Discussion: In the present study, increased age had a positive correlation with the degree of periodontal disease; this is consistent with reports in the literature, which indicate severity of periodontal disease increases with advancing age. In one of the three cases of enamel hypoplasia, the dog owner reported that the dog presented clinical signs compatible with distemper before the teeth changed, corroborating studies that showed that this virus can act on the enamel cells causing hypoplasia lesions. All the deciduous teeth found were dental elements 104, 204, and 304, consistent with literature reports that these teeth are among the most frequently affected by this condition. In the present paper, of all the teeth examined, the canine teeth presented the majority of fractures. Canine teeth are used for grasping and tearing food, and defense, and are more vulnerable to fractures. Dental wear was observed in many dogs in the present study, presenting as loss of dental surface caused by friction, abrasion, or erosion from a variety of causes. Dental wear may be considered as a physiological process as long as it does not compromise function. Dental mobility is an important clinical sign of periodontal disease and generates pain and discomfort to the patient; in the presence of advanced periodontitis, there is a marked loss of periodontal tissues, including alveolar bone, which is an irreversible process. As the dogs evaluated in the present study were older than one year, any absent teeth could be verified as being due to periodontal disease. In conclusion, disorders of the oral cavity have high prevalence in dogs and must receive special attention to be properly diagnosed and treated.

Keywords: tooth, oral cavity, veterinary dentistry. 


\section{INTRODUCTION}

Knowledge of the anatomy of the canine oral cavity is important for evaluation and diagnosis of variations and disorders, and also to aid in therapeutic clinical decision making. Knowledge of normal anatomy for each species in necessary, with respect to number of dental elements, anatomy and physiology, as is knowledge of the main disorders of these structures such as persistence of deciduous teeth, dental wear, dental mobility and fracture, and periodontal disease [6].

On average, a healthy adult dog has 42 teeth: six upper and six lower incisors; two upper and two lower canines; eight upper and eight lower premolars; and four upper and six lower molars. Changes in number of teeth are common, occurring as supernumerary teeth that arise when there is an improper germination leading to division of the dental germ, forming two teeth [13]. Primary dentition (deciduous teeth) may also persist, remaining even after eruption of the permanent teeth, which occurs around seven months of age in dogs [8]. On the other hand, the absence of teeth (hypodontia) may be seen, more commonly in the smaller breeds, which can be hereditary [10].

Among all canine oral disorders, periodontal disease is the most frequently seen. It is usually diagnosed in pets [16], and may present with local and systemic complications [1,2]. The aim of the present study was to determine the occurrence of dental disorders in dogs older than one year of age, coming from the microrregion Ilhéus-Itabuna, Bahia, Brazil.

\section{MATERIALS AND METHODS}

\section{Animals}

We evaluated 74 dogs from the State University of microrregion Ilhéus-Itabuna, Bahia, with any kind of dental disease referred for the surgical treatment. The animals were evaluated immediately prior to treatment. There was no sex or breed predisposition and all dogs were older than one year of age.

\section{Oral cavity evaluation}

To evaluate the oral cavity, the animals were administered pre-anesthetic drugs, comprising acepromazine $0.2 \%$ (Acepran $\left.{ }^{\circledR}\right)^{1}[0.02 \mathrm{mg} / \mathrm{kg}$ intramuscular] in association with morphine (Dimorf®) ${ }^{2}$ [0.5 mg/kg intramuscular], and then induced with propofol $1 \%$ (Propovet $\left.{ }^{\circledR}\right)^{3}$ intravenously at a dose of 5.0 $\mathrm{mg} / \mathrm{kg}$. After intubation, the dogs were maintained in a semi-closed valve circuit with oxygen flow of $50 \mathrm{~mL} /$ $\mathrm{kg} / \mathrm{min}$ with isofluorane $1.0 \mathrm{~V} \%$ (Vetflurano $\left.^{\circledR}\right)^{4}$ and nitrous oxide at 1:1 proportion with oxygen at $100 \%$.

The diagnosis of periodontal disease was based on medical history and physical examination, and the degree of periodontal disease was assessed on the day of surgical treatment with the aid of a millimeter probe with the animal under general anesthesia. The evaluation followed a standardized protocol [15]. All observations regarding the depth of the periodontal pocket, degree of gingivitis, bacterial plaque index, and dental calculus according to visual inspection were recorded on the odontogram [3].

The animals were classified into three groups according to the Di Bello et al. [4] criteria. Dogs with grade I dental calculus, with or without gingivitis, and with gingival pocket $\leq 3 \mathrm{~mm}$ without dental root exposure were classified as having mild periodontal disease. Dogs were classified as having moderate periodontal disease if they had grade II dental calculus, with gingivitis, with gingival pocket $>3 \mathrm{~mm}$ without dental root exposure. The animals that presented with dental calculus, gingivitis, gingival pocket $>3 \mathrm{~mm}$ and dental root exposure were classified as having severe periodontal disease.

Dental elements were evaluated for mobility, wear, fractures, furcation, presence of deciduous teeth, and absent teeth. An absent tooth was confirmed by visual inspection only. All alterations were recorded on the odontogram.

Data analysis

The Pearson correlation test was used to evaluate the correlation between age and the degree of periodontal disease.

\section{RESULTS}

Of the 74 dogs evaluated in the present study, 48 were female and 26 were male. With respect to classification of periodontal disease, 23 had mild disease (mean age, 3.6 years; range, 1-10 years) [Figure 1A], 26 had moderate disease (mean age, 5.7 years; range, 2-10 years) [Figure 1B], and 25 had severe disease (mean age, 9.7 years; range, 5-14 years) [Figure $1 \mathrm{C}$ ]. There was a significant correlation $(0.7 ; P \leq 0.01)$ between age and severity of periodontal disease, with older age associated with a greater degree of periodontal disease.

Of the 74 dogs, 15 had periodontal disease and no other findings. Of the remaining 59, nine had 
a single dental finding and 50 had 2 or more findings. Three dogs had enamel hypoplasia (Figure 2).

Six animals (of the breeds Pinscher, Yorkshire Terrier, and Lhasa Apso) presented with persistent deciduous teeth. All nine persistent deciduous teeth were canines (dental element 104, 204, and 304) [Figure 3]. Ten dogs had dental fractures and of the 11 fractured teeth, three were canines (dental elements 104 and 404), which represented the largest proportion of teeth with this problem (Figure 4).

Dental wear was observed in 25 dogs (Figure 4). Seven animals had furcation exposure (Figure 5) and 10 presented with mobile teeth caused by severe periodontal disease. Dental absence was observed in 47 dogs. All dental alterations are presented in Tables $1,2,3$, and 4 .

\section{DISCUSSION}

All dogs evaluated in the present study had some degree of periodontal disease, and in small animal clinics, periodontal disease is considered the most frequently diagnosed disorder among all the dental and periodontal diseases [5].
Regarding the positive correlation between age and severity of periodontal disease, the present study is in agreement with Harvey et al. [12], who observed that increasing age is positively correlated with increasing severity of periodontal disease.

Enamel hypoplasia was observed in three dogs and one of them with a history of clinical signs of distemper at the moment of the primary teeth eruption. Dubielzig et al. [7] reported that the distemper virus acts directly on the cells of ameloblastic membrane causing typical lesions of hypoplasia.

All deciduous teeth were canines, consistent with Gioso [8] who reported that the most commonly retained teeth are canines and incisors. According to Klein [14], the persistence of deciduous teeth can lead to bacterial plaque accumulation, with formation of dental calculi, functioning as a predisposing and perpetuating factor for periodontal disease. In the present study, the animals with retained deciduous teeth were young and already had signs of more advanced periodontal disease than the dogs of the same age that did not present with deciduous teeth.

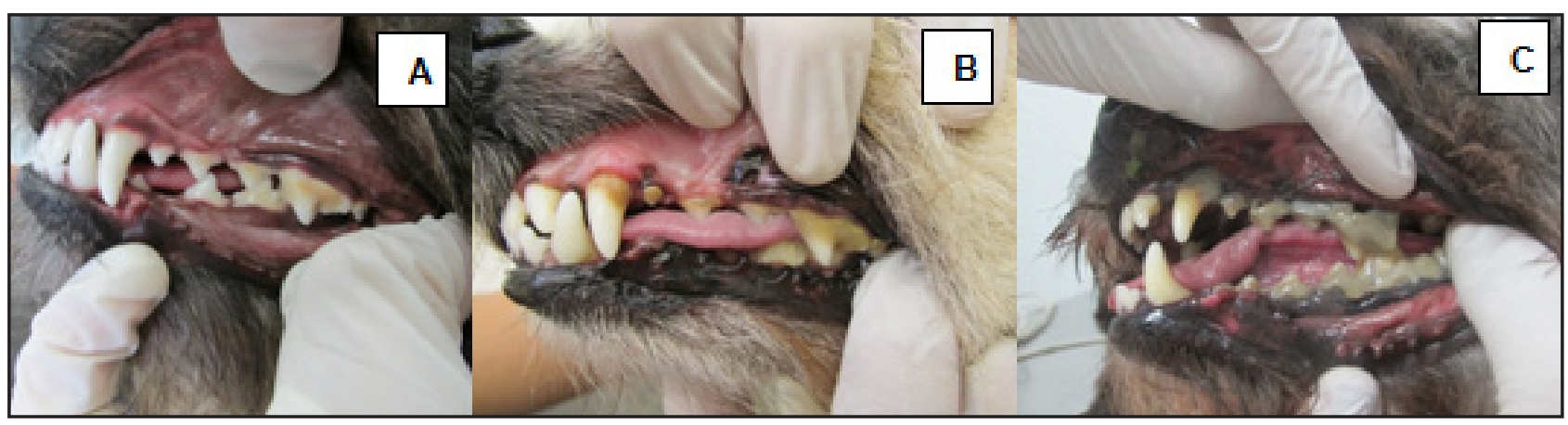

Figure 1. A- Oral cavity of a dog with mild periodontal disease. B- Oral cavity of a dog with moderate periodontal disease. C- Oral cavity of a dog with severe periodontal disease.

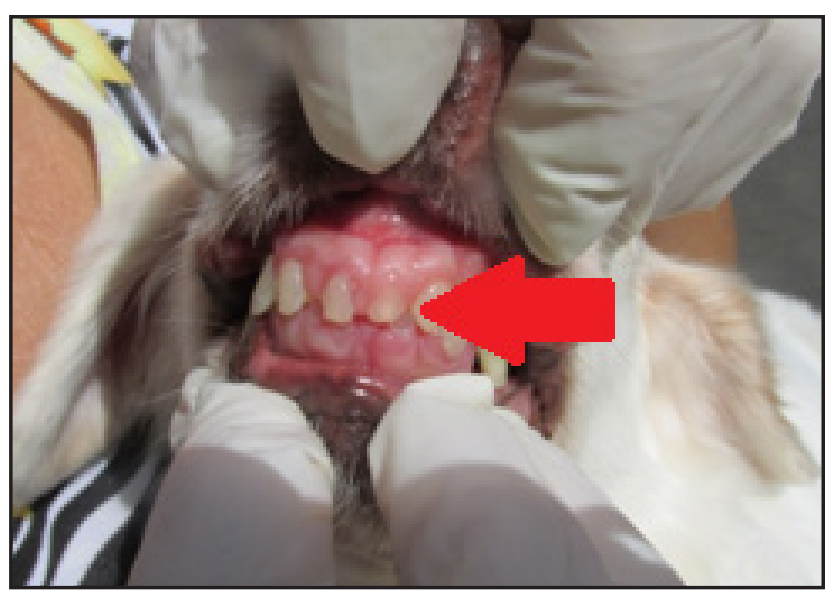

Figure 2. Oral cavity of a dog with enamel hypoplasia (red arrow).

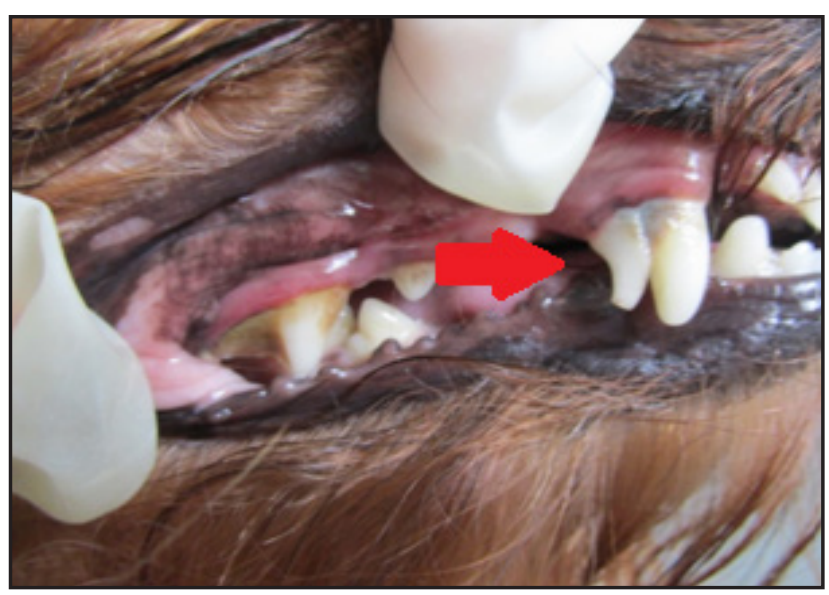

Figure 3. Oral cavity of a dog with deciduous teeth (red arrow). 
L. Sauer, N.G.S.G. Oliveira, L.P.O. Andrade, et al. 2018. Occurrence of Dental Disorders in Dogs.

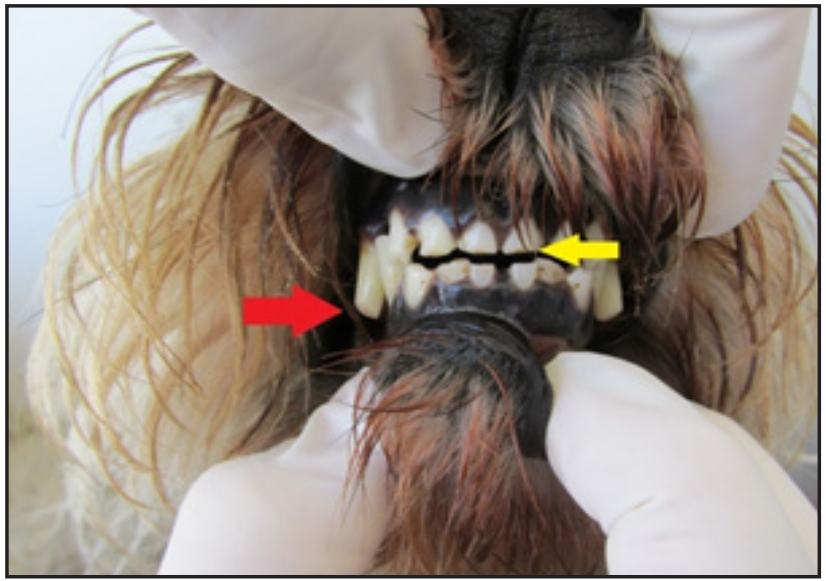

Figure 4. Oral cavity of a dog with dental fracture (red arrow) and dental wear(yellow).

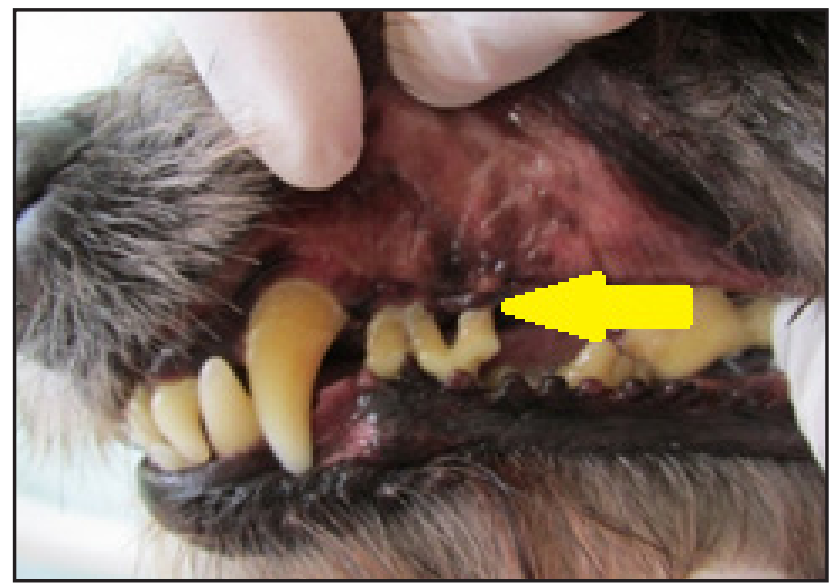

Figure 5. Oral cavity of a dog with furcation (yellow arrow).

Table 1. Alteration of dental elements in the upper right dental arcade in dogs.

\begin{tabular}{|c|c|c|c|c|c|c|}
\hline \multicolumn{7}{|c|}{ Upper teeth (maxilla) right side } \\
\hline Teeth elements & Primary & Fracture & Wear & Mobility & Absence & Furcation \\
\hline First incisor (101) & & & 11 & & 7 & \\
\hline Second incisor (102) & & & 10 & & 2 & \\
\hline Third incisor (103) & & 1 & 4 & & 6 & \\
\hline Canine (104) & 4 & 2 & 4 & & 2 & \\
\hline First premolar (105) & & 1 & 4 & & 19 & \\
\hline Second premolar (106) & & & 4 & 2 & 6 & 2 \\
\hline Third premolar (107) & & & 1 & 1 & 5 & \\
\hline First molar (108) & & 1 & 2 & & 1 & 3 \\
\hline Second molar (109 & & & & & 1 & \\
\hline Third molar (110) & & & & & 17 & \\
\hline Total & 4 & 5 & 40 & 3 & 66 & 5 \\
\hline
\end{tabular}

Table 2. Alteration of dental elements in the upper left dental arcade in dogs.

\begin{tabular}{|c|c|c|c|c|c|c|}
\hline \multicolumn{7}{|c|}{ Upper teeth (maxilla) left side } \\
\hline Teeth elements & Primary & Fracture & Wear & Mobility & Absence & Furcation \\
\hline First incisor (201) & & & 10 & & 3 & \\
\hline Second incisor (202) & & 1 & 10 & 2 & 2 & \\
\hline Third incisor (203) & & & 4 & & 4 & \\
\hline Canine (204) & 4 & & 4 & & & \\
\hline First premolar (205) & & 1 & 2 & 1 & 17 & 1 \\
\hline Second premolar (206) & & & 7 & 1 & 7 & 4 \\
\hline Third premolar (207) & & & 4 & & 4 & 4 \\
\hline First molar (208) & & 1 & 3 & & 1 & 4 \\
\hline Second molar (209) & & & & & 1 & \\
\hline Third molar (210) & & & & & 15 & \\
\hline Total & 4 & 3 & 44 & 4 & 54 & 13 \\
\hline
\end{tabular}


L. Sauer, N.G.S.G. Oliveira, L.P.O. Andrade, et al. 2018. Occurrence of Dental Disorders in Dogs.

Acta Scientiae Veterinariae. 46: 1600.

Table 3. Alteration of dental elements in the lower left dental arcade in dogs.

\begin{tabular}{|c|c|c|c|c|c|c|}
\hline \multicolumn{7}{|c|}{ Lower teeth (mandible) left side } \\
\hline Teeh elements & Primary & Fracture & Wear & Mobility & Absence & Furcation \\
\hline First incisor (301) & & & 11 & 2 & 6 & \\
\hline Second incisor (302) & & & 10 & 3 & 2 & \\
\hline Third incisor (303) & & & 8 & 1 & 3 & \\
\hline Canine (304) & 1 & & 3 & & & \\
\hline First premolar (305) & & & & 1 & 12 & \\
\hline Second premolar (306) & & & 1 & 1 & 8 & \\
\hline Third premolar (307) & & 1 & & & & \\
\hline First molar (308) & & & & & & \\
\hline Second molar (309) & & & & 1 & 2 & \\
\hline Third molar (310) & & & & 1 & 10 & \\
\hline Total & 1 & 1 & 33 & 10 & 43 & 0 \\
\hline
\end{tabular}

Table 4. Alteration of dental elements in the lower right dental arcade in dogs.

\begin{tabular}{|c|c|c|c|c|c|c|}
\hline \multicolumn{7}{|c|}{ Lower teeth (mandible) right side } \\
\hline Teeth elements & Primary & Fracture & Wear & Mobility & Absence & Furcation \\
\hline First incisor (401) & & & 14 & 1 & 5 & \\
\hline Second incisor (402) & & & 11 & 3 & 2 & \\
\hline Third incisor (403) & & & 8 & 1 & 4 & \\
\hline Canine (404) & & 1 & 2 & & & \\
\hline First premolar (405) & & & 1 & 2 & 8 & \\
\hline Second premolar (406) & & & 1 & 2 & 9 & \\
\hline Third premolar (407) & & 1 & & & 2 & \\
\hline \multicolumn{7}{|l|}{ First molar (408) } \\
\hline Second molar (409) & & & & & 4 & \\
\hline Third molar (410) & & & & & 11 & \\
\hline Total & 0 & 2 & 37 & 9 & 45 & 0 \\
\hline
\end{tabular}

In the present study, the majority of teeth that presented with fractures were canines, which, according to literature, are more vulnerable to trauma due to their position in the oral cavity. In addition, canine teeth are involved in capturing food and for defense, increasing their vulnerability; the frequency of fractures presenting in canine teeth is reported to be between $35.5 \%$ and $57.1 \%[9,18]$. Dental wear in the evaluated dogs mainly affected the incisors, which has also been described in wild dogs by Rossi Junior et al. [17].

Dental mobility is an important clinical sign of periodontal disease; mobile teeth lead to pain and discomfort to the patient [8], a condition that was observed in several animals in the present study. Dental mobility occurs because advanced periodontitis causes a marked loss of periodontal tissues, with bone loss of more than $50 \%$ [11].

\section{CONCLUSIONS}

The majority of dogs older than one year have some type of dental alteration, among which periodontal disease is the most common. Worsening periodontal disease is related to the increasing age of the animal.

\section{MANUFACTURERS}

${ }^{1}$ Vetnil Produtos Veterinários. Louveira, SP, Brazil.

${ }^{2}$ Cristália - Produtos Químicos Farmacêuticos Ltda. São Paulo, SP, Brazil.

${ }^{3}$ Ourofino Saúde Animal. Cravinhos, SP, Brazil. 
L. Sauer, N.G.S.G. Oliveira, L.P.O. Andrade, et al. 2018. Occurrence of Dental Disorders in Dogs.

Acta Scientiae Veterinariae. 46: 1600.

${ }^{4}$ Virbac. São Paulo, SP, Brazil.

Funding. This research was supported by State University of Santa Cruz (UESC).

Ethical approval. This study was approved by the Ethics Committee for the Use of Animals of the State University of Santa Cruz (protocol no. 022/2014)
Acknowledgments. We would like to thank State University of Santa Cruz (UESC) and Coordenação de Aperfeiçoamento de Pessoal de Nível Superior (CAPES) for granting us scholarships. Declaration of interest. The authors report no conflicts of interest. The authors alone are responsible for the content and writing of the paper.

\section{REFERENCES}

1 Braga S., Braga D. \& Soares S. 2009. Diabetes mellitus e periodontite - um caso de saúde oral. Revista Portuguesa de Estomatologia, Medicina Dentária e Cirurgia Maxilofacial. 50: 111-117.

2 Brook A. \& Niemiec D.V.M. 2008. Periodontal disease - topical review. Topics in Companion Animal Medicine. 23(2): 72-80.

3 Corrêa H.L., Venturini M. \& Gioso M.A. 1998. Registro do exame clínico odontológico, odontograma. Clínica Veterinária. 13: 23-28.

4 Di Bello A., Buonavoglia A., Franchini D., Valastro C., Ventrella G., Greco MF. \& Corrente M. 2014. Periodontal disease associated with red complex bacteria in dogs. Journal of Small Animal Practice. 55: 160-163.

5 Dillon R. 1984. A cavidade oral. In: Kirk R.W. (Ed). Atualização terapêutica veterinária: pequenos animais.7.ed. São Paulo: Manole, pp.952-975.

6 Domingues L.M., Alessi A.C., Schoken-Iturrino R.P. \& Dutra L.S. 1999. Oral flora associated with periodontal disease in dogs. Arquivo Brasileiro Medicina Veterinária Zootenia. 51: 329-332.

7 Dubielzi R.R., Higgins R.J. \& Krakowka S. 1981. Lesions of the enamel organ of developing dog teeth following experimental inoculation of ginotobiotic puppies with canine distemper virus. Veterinary Pathology. 18: 684-689.

8 Gioso M.A. 2007. Doença Periodontal. In: Odontologia Veterinária para o clínico de pequenos animais. 2.ed. São Paulo: Manole, pp.7-24.

9 Golden A.L., Stoller M. \& Harvey C.E. 1982. A survey of oral and dental diseases in dogs anesthetized at a veterinary hospital. Journal of the America Animal Hospital Association. 18: 891-899.

10 Harvey C.E. \& Emily P.P. 1993. Occlusion, occlusive abnormalities, and orthodontic treatment. In: Small Animal Dentistry. St. Louis: Mosby, pp.266-269.

11 Harvey C.E. \& Emily P.P. 1993. Restorative dentistry. In: Small Animal Dentistry. St Louis: Mosby, pp.213-265.

12 Harvey C.E., Shofer F.S. \& Laster L. 1994. Association of age and body weight with periodontal disease in North American dogs. Journal of Veterinary Dentistry. 11: 94-105.

13 Hoskins J.D. 1993. O sistema digestivo. In: Pediatria veterinária: cães e gatos até 6 meses de idade. São Paulo: Manole, pp.153-222.

14 Klein T. 2000. Predisposing factors and gross examination findings in periodontal disease. Clinical Techniques in Small Animal Practice. 15(4):189-196.

15 Logan E.I. \& Boyce E.N. 1994. Oral health assessment in dogs: parameters and methods. Journal of Veterinary Dentistry, 11(2): 58-63.

16 Lund E.M., Armstrong P.J., Kirk C.A., Kolar L.M. \& Klausner J.S. 1999. Health status and population characteristics of dogs and cats examined at private veterinary practices in the United States. Journal of the American Veterinary Medical Association. 214: 1336-1341.

17 Rossi Junior J.L., Castro A.P.A. \& Marchesi M.D. 2013. Evaluation of dental changes in sincranium of Cerdocyon thous from running over in the ES-060 road, Espirito Santo. Pesquisa Veterinária Brasileira. 33(6): 785-790.

18Soukup J.W., Hetzel S. \& Paul A. 2015. Classification and epidemiology of traumatic dentoalveolar injuries in dogs and cats: 959 injuries in 660 patient visits (2004-2012). Journal of Veterinary Dentistry. 32(1): 6-14. 